\title{
An update on the anxiolytic and neuroprotective properties of etifoxine: from brain GABA modulation to a whole-body mode of action
}

This article was published in the following Dove Press journal:

Neuropsychiatric Disease and Treatment

\author{
Philippe Nuss ${ }^{1,2}$ \\ Florian Ferreri ${ }^{1}$ \\ Michel Bourin ${ }^{3}$ \\ 'Department of Adult Psychiatry and \\ Medical Psychology, Sorbonne University, \\ Saint-Antoine Hospital, Paris, France; \\ ${ }^{2}$ Inserm UMR_S938, Saint-Antoine \\ Research Centre, Sorbonne University, \\ Paris, France; ${ }^{3}$ Department of \\ Neurobiology of Anxiety and Depression, \\ Faculty of Medicine, Nantes University, \\ Nantes, France
}

\begin{abstract}
Treating the signs and symptoms of anxiety is an everyday challenge in clinical practice. When choosing between treatment options, anxiety needs to be understood in the situational, psychiatric, and biological context in which it arises. Etifoxine, a nonbenzodiazepine anxiolytic drug belonging to the benzoxazine class, is an effective treatment for anxiety in response to a stressful situation. In the present review, we focused on several aspects of the cerebral and somatic biological mechanisms involved in anxiety and investigated the extent to which etifoxine's mode of action can explain its anxiolytic activity. Its two mechanisms of action are the modulation of GABAergic neurotransmission and neurosteroid synthesis. Recent data suggest that the molecule possesses neuroprotective, neuroplastic, and anti-inflammatory properties. Etifoxine was first shown to be an effective anxiolytic in patients in clinical studies comparing it with clobazam, sulpiride, and placebo. Randomized controlled studies have demonstrated its anxiolytic efficacy in patients with adjustment disorders (ADs) with anxiety, showing it to be superior to buspirone and comparable to lorazepam and phenazepam, with a greater number of markedly improved responders and a better therapeutic index. Etifoxine's noninferiority to alprazolam has also been demonstrated in a comparative trial. Significantly less rebound anxiety was observed after abrupt cessation of etifoxine compared with lorazepam or alprazolam. Consistent with this finding, etifoxine appears to have a very low dependence potential. Unlike lorazepam, it has no effect on psychomotor performance, vigilance, or free recall. Severe adverse events are in general rare. Skin and subcutaneous disorders are the most frequently reported, but these generally resolve after drug cessation. Taken together, its dual mechanisms of action in anxiety and the positive data yielded by clinical trials support the use of etifoxine for treating the anxiety signs and symptoms of individuals with ADs.
\end{abstract}

Keywords: etifoxine, adjustment disorders, TSPO, translocator protein $18 \mathrm{kDa}, 3 \alpha$, allopregnanolone, $5 \alpha$-THP, GABA, benzodiazepines, anxiety, neuroprotection

\section{Introduction}

Anxiety, an emotional experience characterized by a state of arousal and the expectation of danger, has been part of human experience throughout the ages. Over time, numerous conceptions of anxiety and classifications have been proposed, particularly in the medical field. Classifications of anxiety regularly redraw the boundaries between its different clinical manifestations, and new research continues to reveal further layers of complexity in its pathophysiological mechanisms. In the present review, we focused on the treatment of anxiety with etifoxine, a non-benzodiazepine (BZD) anxiolytic. Our aim was to provide an overall picture
Correspondence: Philippe Nuss

Department of Psychiatry and Medical Psychology, Hospital Saint-Antoine, 184 rue du Faubourg Saint-Antoine, Paris 750I2, France

Email nuss.philippe@gmail.com 
of the anxiolytic properties of etifoxine, both within the traditional conceptual framework of anxiety disorders and with respect to the new perspectives opened up by recent research.

We focused on the treatment of adjustment disorders (ADs), a category that was recently redefined in the DSM-5 and ICD-11. Previously, the emphasis was on subjective distress and emotional disturbances in ADs, principally in terms of anxious or depressive symptomatology, leading to the identification of ADs with anxiety (ADWA) and ADs with depression. ADWA were described as being more frequent than their depressive counterpart, mainly affecting young and professionally active individuals. ${ }^{1}$ The manifestations of anxiety in ADWA were considered to be just as severe as those of generalized anxiety disorders. ${ }^{2}$ Nonetheless, criticisms were voiced regarding the validity of the DSM-IV and ICD-10 diagnostic criteria for ADs. Some of these have been addressed in the newly published classifications, where there has been a shift towardconceptualizing $\mathrm{ADs}$ as trauma- and stressor-related disorders. DSM-5 diagnostic criteria for ADs include transient maladaptive or pathological reactions to identifiable stressors or changes in life circumstances, with symptoms emerging within 3 months of stress or onset. Anxiety, depression, and behavioral disturbances are now seen as potentially associated qualifiers, rather than as specifiers. Clinical manifestations are described as being out of all proportion with the event. In addition to its intrinsic nature, the stressor must be seen within the personal and interpersonal context in which it has occurred, and cultural norms. The ICD-11 classification goes one step further, by identifying core clinical manifestations, namely 1) "preoccupation with the stressor or its consequences, including excessive worry, recurrent and distressing thoughts about the stressor, or constant rumination about its implications", and 2) "failure to adapt to the stressor that causes significant impairment in personal, family, social, educational, occupational, or other important areas of functioning". If functioning is maintained, it is done so only through significant additional effort, and if impairment takes place, it must be far greater that it would be expected, given the individual's prior functioning.

A better definition of ADs might make it possible to identify associated CNS and whole-body biomarkers, based on the psychobiology of trauma and stressor, and ultimately improve their treatment. In particular, it is important to study the role of GABA in $\mathrm{AD}^{3}$ along with neuroendocrine and whole-body processes such as inflammation, immunity, and oxidative stress. ${ }^{4}$
The traditional concept of the pathophysiology of anxiety has focused on structural and functional brain dysfunction. ${ }^{5}$ It regards anxiety as the result of an alteration of the coordinated activity of brain pathways, modulated by local and distant synaptic relays via neurotransmitters. Structurally, a set of limbic structures have been implicated in anxiety. These include the amygdala, which is tightly connected to the prefrontal cortex and appears to be critical for the regulation of negative emotion. Various neurotransmitters and modulators play an important functional role in modulating anxiety-related behaviors. These include mediators associated with the hypothalamic-pituitary-adrenal (HPA) axis,6 monoaminergic and GABAergic neurotransmission systems, ${ }^{7,8}$ neuropeptides such as cholecystokinin, and lipid neuromodulators. ${ }^{9}$

In addition to this brain-centered approach to the pathophysiology of anxiety, there is increasing evidence to suggest that anxiety states can also be modulated by the effect on the brain of somatic physiological processes such as inflammation, immunity, and oxidative stress, as well as gut microbiota. ${ }^{10}$ For instance, dysfunctional interactions involving the HPA axis and gut microbiota $^{11}$ have been described as contributing to the pathophysiology of anxiety. In humans, stress, a common feature of all anxiety disorders has been shown to be associated with several proinflammatory response phenotypes that may be unresponsive to the anti-inflammatory actions of glucocorticoids. ${ }^{12}$ Moreover, several drugs known to reduce the clinical manifestations of anxiety (antidepressants, certain BZD, and non-BZD anxiolytics) have been shown to attenuate the above-mentioned abnormal physiological processes, pointing to a possible - and previously underestimated - aspect of the mechanism of action of anxiolytic drugs. ${ }^{13}$

Current understanding and treatment of anxiety disorders may thus need to be broadened in order to adopt a whole-body perspective. In particular, we need to reappraise our understanding of the mechanisms of action of anxiolytic drugs to include newly identified mechanisms within or without the CNS. Etifoxine, a non-BZD anxiolytic molecule that acts as a positive allosteric modulator of GABAergic transmission, is no exception to this rule. Recent studies have shown that etifoxine can exhibit considerable anti-inflammatory activity in the CNS. ${ }^{14}$ Effects on the immune system ${ }^{15}$ and neuroendocrine system, notably through binding to the mitochondrial outer membrane translocator protein (TSPO) ${ }^{16}$ and neurotrophic factor synthesis, ${ }^{17}$ may also contribute to etifoxine's anxiolytic activity. This approach is opening up novel and exciting 
avenues for exploring the mechanisms of action of this anxiolytic agent.

Strategies for treating anxiety disorders are inspired by evidenced-based studies, along with empirical experimentation with drugs. Given the wide variety of clinical settings in which the manifestations of anxiety can arise and the chronicity of these manifestations, it is unrealistic to expect to find a single, optimum evidence-based treatment for all clinical situations. Clinicians, therefore, need to gain a deeper understanding of the diverse mechanisms of action of anxiolytic agents, in order to select the most promising anxiolytic medication for their patients.

In this context, we conducted a detailed review of the mechanisms through which etifoxine exerts its anxiolytic activity. Looking beyond the classical $\mathrm{GABA}_{\mathrm{A}}$ receptor interactions we present new research data about etifoxine's other putative anxiolytic mechanisms.

\section{Interactions of etifoxine with the $\mathrm{GABA}_{\mathbf{A}}$ receptor Role of $\mathrm{GABA}_{\mathrm{A}}$ neurotransmission in the pathophysiology of anxiety}

Both animal research and brain imaging studies have demonstrated that prolonged dysregulation of brain networks involving cortical and specific subcortical areas (amygdala, hippocampus, thalamus, prefrontal, and cingulate cortex) contributes to the expression of anxiety symptoms. ${ }^{5}$ In particular, reduced inhibitory GABAergic transmission in the CNS has been shown to be critical for the manifestation of anxiety. ${ }^{18}$ In this respect, the structure and function of the $\mathrm{GABA}_{\mathrm{A}}$ receptor have been under intense scrutiny.

The $\mathrm{GABA}_{\mathrm{A}}$ receptor is a ligand-gated chlorideselective ion channel. It is a hetero-oligomeric protein made up of five subunits that cross the neuronal membrane. Most $\mathrm{GABA}_{\mathrm{A}}$ receptors include two $\alpha$ subunits, two $\beta$ subunits, and one $\gamma$ subunit. ${ }^{19}$ The $\alpha$ and $\beta$ subunits enable GABA binding, while the $\gamma$ subunit confers BZD sensitivity, as these drugs bind within the interface between the $\alpha$ and $\gamma$ subunits, enhancing the probability of a channel opening in response to GABA. ${ }^{20}$ The opening of this chloride/ bicarbonate-permeable channel ${ }^{21}$ by at least two GABA molecules induces an influx of negatively charged chloride ions, resulting in a transient reduction in the ability of the neuronal membrane to conduct action potentials, leading to phasic inhibition of the neuron. The anxiolytic effect of drugs binding to the $\mathrm{GABA}_{\mathrm{A}}$ receptor is attributed to the facilitation of chloride channel opening, thereby amplifying neuronal inhibition in response to GABA.

Over the last half-century, numerous $\mathrm{GABA}_{\mathrm{A}}$ receptor ligands have been developed as therapeutic agents, including anxiolytics, hypnotics, muscle relaxants, and antiepileptics. One such anxiolytic drug is etifoxine (6-chloro-2-ethylamino-4-methyl-4-phenyl-4H-3,1-benzoxazine), a non-BZD anxiolytic drug belonging to the benzoxazine class. ${ }^{22-24}$ The affinity of etifoxine for the chloride channel coupled to the $\mathrm{GABA}_{\mathrm{A}}$ receptor is in the micromolar range, whereas that of BZDs for this same channel are in the nanomolar range. ${ }^{25}$ Etifoxine has a dual mechanism of action on GABAergic transmission, through both a direct effect on the GABA receptor and an indirect effect via neurosteroid synthesis allowing for allosteric modulation of the $\mathrm{GABA}_{\mathrm{A}}$ receptor. $^{26,27}$

\section{Direct action of etifoxine on the $\mathrm{GABA}_{\mathrm{A}}$ receptor}

In vitro studies have demonstrated that etifoxine can inhibit the binding of a specific $\mathrm{GABA}_{\mathrm{A}}$ receptor ligand (t-butylbiclophosphorothionate, TBPS) in the cerebral cortex of rodents, suggesting the presence of binding sites for etifoxine on the $\mathrm{GABA}_{\mathrm{A}}$ receptor. In vivo evidence of a functional consequence of etifoxine binding to the $\mathrm{GABA}_{\mathrm{A}}$ receptor has come from studies in mice, where etifoxine has been found to block the clonic seizures induced by TBPS, demonstrating an anticonvulsant effect mediated through the $\mathrm{GABA}_{\mathrm{A}}$ receptor. ${ }^{25}$

More detailed information on the nature of the interaction between etifoxine and the $\mathrm{GABA}_{\mathrm{A}}$ receptor has been yielded by radioligand binding studies evaluating competition from etifoxine for the binding sites of the GABA agonist $\left[{ }^{3} \mathrm{H}\right]$-muscimol and the BZD modulator $\left[{ }^{3} \mathrm{H}\right]-$ flunitrazepam on the $\mathrm{GABA}_{\mathrm{A}}$ receptor. In vitro experiments on rat brain membrane preparations ${ }^{28}$ have shown that the binding of these ligands is not hindered by etifoxine, indicating that its binding site is distinct from that of GABA and BZDs. Instead, the binding of these two radio-labeled ligands increases in the presence of etifoxine, demonstrating positive allosteric modulation. The in vivo observation that the anxiolytic action of etifoxine is not inhibited by flumazenil, a specific antagonist of the BZD binding site on the $\mathrm{GABA}_{\mathrm{A}}$ receptor, ${ }^{29}$ is also consistent with the notion that etifoxine and BZDs bind to different sites. This property may explain the lack of a detrimental effect of etifoxine on sedation and memory compared with BZDs (Figure 1). 


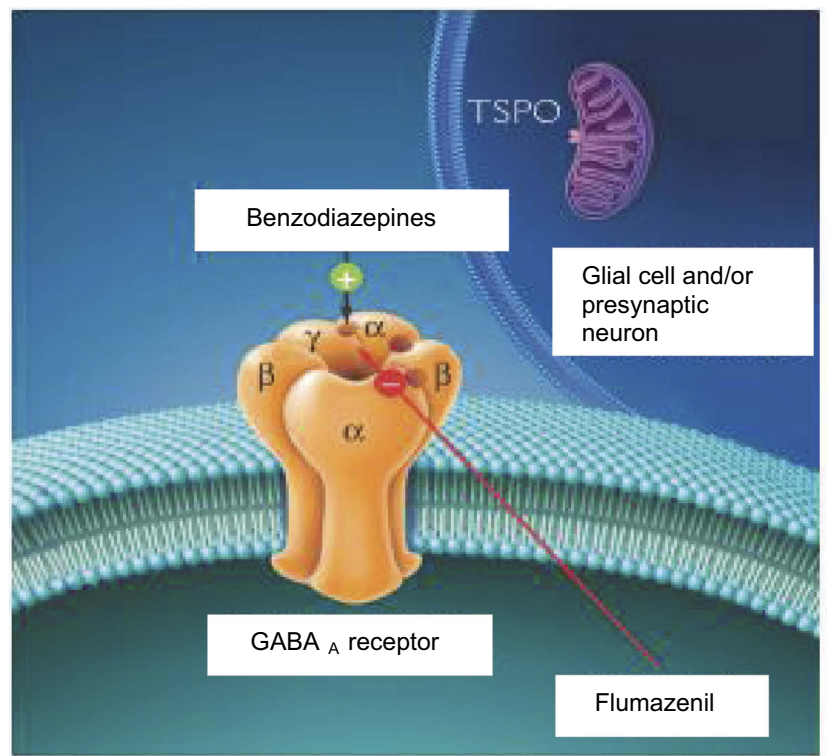

A

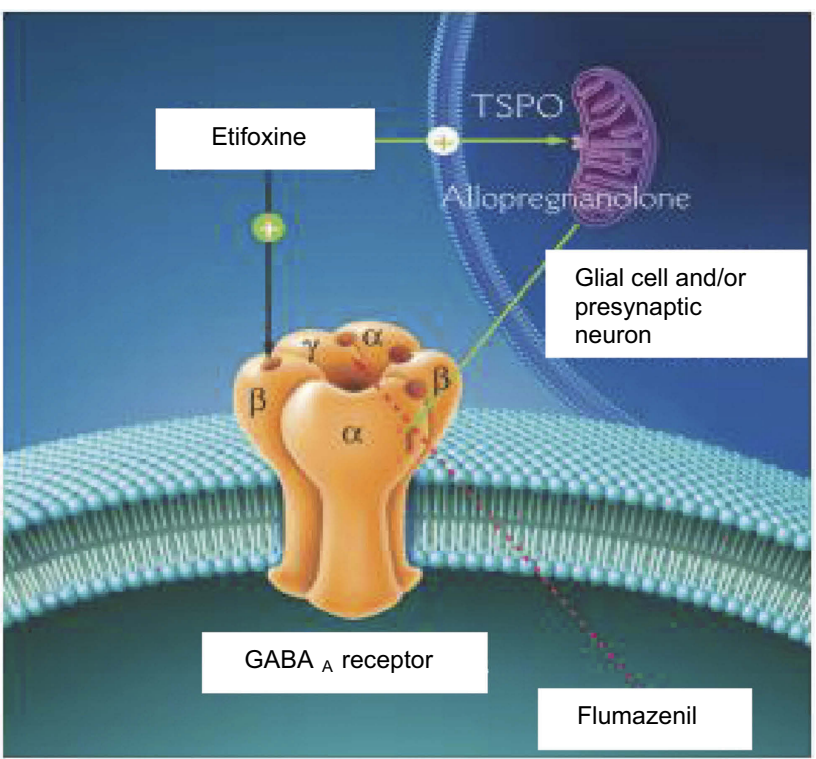

B

Figure I Comparison of the mechanism of action of etifoxine and benzodiazepines on the GABA $A_{A}$ receptor. (A) Benzodiazepines bind principally within the between the $\boldsymbol{\alpha}$ and $\gamma_{2}$ subunits of the $\mathrm{GABA}_{A}$ receptor. The nature of the $\alpha$ subunit influences the pharmacological properties of agents binding to it (sedation, myorelaxation, amnesia, etc). Flumazenil specifically inhibits binding of benzodiazepines to the $G A B A_{A}$ receptor. (B) Etifoxine acts on the $G A B A_{A}$ receptor, both by binding directly to the $\boldsymbol{\beta}_{2} / \boldsymbol{\beta}_{3}$ subunits and by indirectly stimulating neurosteroid production (allopregnanolone). Flumazenil does not affect the binding of etifoxine to the $\mathrm{GABA}_{\mathrm{A}}$ receptor. Reproduced with kind permission from Biocodex.

Abbreviation: TSPO, translocator protein of $18 \mathrm{kDa}$.

Studies of recombinant $\mathrm{GABA}_{\mathrm{A}}$ receptors have shown that etifoxine-stimulated GABAergic transmission persists in the absence of $\alpha$ or $\gamma$ subunits, suggesting that it is the $\beta$ subunit of the $\mathrm{GABA}_{\mathrm{A}}$ receptor that is critical for etifoxine binding. The different subunits of the $\mathrm{GABA}_{\mathrm{A}}$ receptor hetero-oligomer vary from one another in the composition of a limited set of amino acid sequences, each family is made up of a restricted number of variants. Several subtypes of the $\mathrm{GABA}_{\mathrm{A}}$ receptor are present within the CNS, and these subtypes show specific anatomical and subcellular expression patterns, as well as functionally different properties. The apparent affinity of $\mathrm{GABA}_{\mathrm{A}}$ receptors for GABA and etifoxine depends on the subunit composition and, more specifically, on $\alpha-\beta$ subunit dimers forming the agonist binding sites for GABA. In this context, etifoxine has a higher affinity for receptors containing $\beta_{2}$ or $\beta_{3}$ subunits than for ones containing $\beta_{1}$ subunits. ${ }^{30}$ The effects of etifoxine are thus mainly determined by the presence of $\beta$ subunits, which clearly distinguishes this anxiolytic drug from other positive allosteric modulators of the $\mathrm{GABA}_{\mathrm{A}}$ receptor, such as BZDs whose activity depends primarily on the nature of the $\alpha$ and $\gamma$ subunits. ${ }^{31}$ The binding of etifoxine to $\beta$ subunits leads to a positive allosteric modulation of the chloride currents resulting from the opening of $\mathrm{GABA}_{\mathrm{A}}$ receptors, associated with an increase in the current duration and amplitude in the case of non-saturating GABA concentrations. Etifoxine has also been shown to increase the frequency of spontaneous miniature GABAergic inhibitory post-synaptic currents, without changing their amplitude or kinetic characteristics. ${ }^{3}$

The behavioral consequences of this subunit specificity were elegantly demonstrated by Verleye et al. Two different inbred mouse strains (BALB/cByJ and C57BL/6J) were compared on emotional and anxious behavior. An overexpression of the $\beta_{2}$ subunit in the CNS was found in the BALB/cByJ mice, compared with the C57BL/6J mice, and the former were more reactive to stressful stimuli than the latter. ${ }^{32}$ No differences in $\beta_{3}$ subunits were found between the two strains. The BALB/cByJ strain was also more responsive to the anxiolytic and antiepileptic effects of etifoxine, indicating a positive correlation between the proportion of $\beta_{2}$-containing $\mathrm{GABA}_{\mathrm{A}}$ receptor subunits and etifoxine efficacy. ${ }^{33}$

\section{Indirect action of etifoxine on the $\mathrm{GABA}_{\mathrm{A}}$ receptor}

In addition to its direct action on the $\mathrm{GABA}_{\mathrm{A}}$ receptor through binding to the $\beta$-subunit, etifoxine can displace $\left[{ }^{3} \mathrm{H}\right]-\mathrm{PK} 11195$, a highly specific TSPO ligand, in a concentration-dependent manner. ${ }^{16,34}$ The exact role of 
TSPO in neurosteroid synthesis within the neurons and glial cells of the CNS - particularly that induced by etifoxine - is not as clear today as it used to be. ${ }^{35}$ TSPO was initially thought to be located at the contact zone between the outer and inner mitochondrial membranes, and to be key in orchestrating mitochondrial cholesterol translocation, playing the role of the rate-limiting step of neurosteroidogenesis. However, a recent experiment showing that TSPO-/mouse line is not modified in steroidogenesis ${ }^{36,37}$ and that PK11195 can stimulate steroidogenesis even in the absence of TSPO, points to the existence of another target molecule. ${ }^{38}$ A study in frog hypothalamus explant published the same year demonstrated that etifoxine may act through a mechanism that is independent of TSPO, leading to an increase in neurosteroidogenesis. ${ }^{16}$

Certain neurosteroids produced in the mitochondria interact with the $\mathrm{GABA}_{\mathrm{A}}$ receptor. Pregnenolone, which is synthesized from cholesterol in the mitochondria, is converted to progesterone by $3 \alpha$-hydroxysteroid dehydrogenase. In turn, progesterone is converted in the cytoplasm to its $3 \alpha, 5 \alpha$-derivatives ( $3 \alpha, 5 \alpha$-tetrahydroprogesterone or allopregnanolone, and allotetrahydrodeoxy corticosterone or alloTHDOC) by successive actions of $5 \alpha$-reductase and $3 \alpha$-hydroxysteroid dehydrogenase. Of interest, progesterone, deoxycorticosterone, and testosterone metabolites, particularly allopregnanolone, are the most potent known positive allosteric modulators of $\mathrm{GABA}_{\mathrm{A}}$ receptors. ${ }^{39}$ They increase the opening burst duration of the $\mathrm{GABA}_{\mathrm{A}}$ receptor channel, as well as the mean open time. ${ }^{21}$

The increase in brain allopregnanolone levels after etifoxine administration observed in animal models is assumed to have a synergistic and facilitatory effect on GABAergic neurotransmission, ${ }^{27}$ complementing the direct action of etifoxine on the $\beta$ subunit of the $\mathrm{GABA}_{\mathrm{A}}$ receptor. Etifoxine's molecular mechanism of action (Figure 2) is thus ascribed both to its direct effect on the $\mathrm{GABA}_{\mathrm{A}}$ receptor and to an indirect effect on the receptor via increased synthesis of certain neurosteroids as a consequence of binding to and activating TSPO. ${ }^{40,41}$

This dual mechanism of action has been correlated with the anxiolytic effect of etifoxine observed in animal models of anxiety. ${ }^{42,43}$ For instance, this effect was confirmed in a study of anxious BALB/cByJ mice subjected to acute immobilization stress. The effects of different substances blocking central GABAergic function or neuroactive steroid synthesis were also evaluated. ${ }^{44}$ The authors concluded that by binding to distinct recognition sites on the $\mathrm{GABA}_{\mathrm{A}}$ receptor, etifoxine, and allopregnanolone exert additive effects in potentiating inhibitory GABAergic transmission, reflected in an increased anticonvulsive effect. ${ }^{45}$

\section{Etifoxine and the serotonergic system}

Other neurotransmitter systems besides the GABAergic system, such as the serotonergic system, are also involved in anxious behavior. Given the numerous interactions between these two neurotransmission systems, it is relevant to investigate possible interactions between etifoxine and serotonergic receptor ligands. Bourin et al, demonstrated in a mouse model of anxiety that the anxiolytic effect of etifoxine is modulated by the co-administration of $5-\mathrm{HT}_{2 \mathrm{~A}}$ ligands. ${ }^{46} \mathrm{~A}$ serotonergic mechanism is thus involved in the anxiolytic effect of etifoxine. As etifoxine has no direct interaction with the serotonergic system, these results suggest that the anxiolytic activity of etifoxine is subtended by a relationship between the serotonergic and GABAergic systems.

\section{Behavioral pharmacology of etifoxine: manifestations of anxiety}

Several studies have evaluated the direct or indirect GABAergic mechanisms through which etifoxine regulates autonomic responses associated with anxiety.

Etifoxine's effects on autonomic responses to stress have been investigated in rat models of anxiety (stressinduced hyperthermia, conditioned fear stress-induced freezing behavior, and activation of colon motility). Etifoxine treatment attenuated hyperthermia, and reduced freezing behavior and the frequency of caeco-colonic contractions in rats subjected to stressful events. The anxiolytic effects of etifoxine thus involve attenuation of both behavioral and autonomic manifestations of anxiety. ${ }^{47}$

Another animal model, which used the cerebral injection of corticotrophin-releasing factor (CRF) to reproduce autonomic and behavioral responses to stress, showed that the anxiolytic properties of etifoxine are related to its effect on GABAergic neurotransmission, rather than to an interaction with CRF1 and CRF2 receptors. ${ }^{48}$

GABAergic involvement in the anxiolytic and anticonvulsant properties of etifoxine has also been highlighted in a mouse alcohol withdrawal model, in which hyperexcitability and anxiety in mice with alcohol withdrawal symptoms were reduced by etifoxine. ${ }^{49}$

In the four-plate test model of anxiety, the anxiolytic activity of both etifoxine and gabapentin was found to be comparable to that of a BZD (diazepam) or a serotonergic 


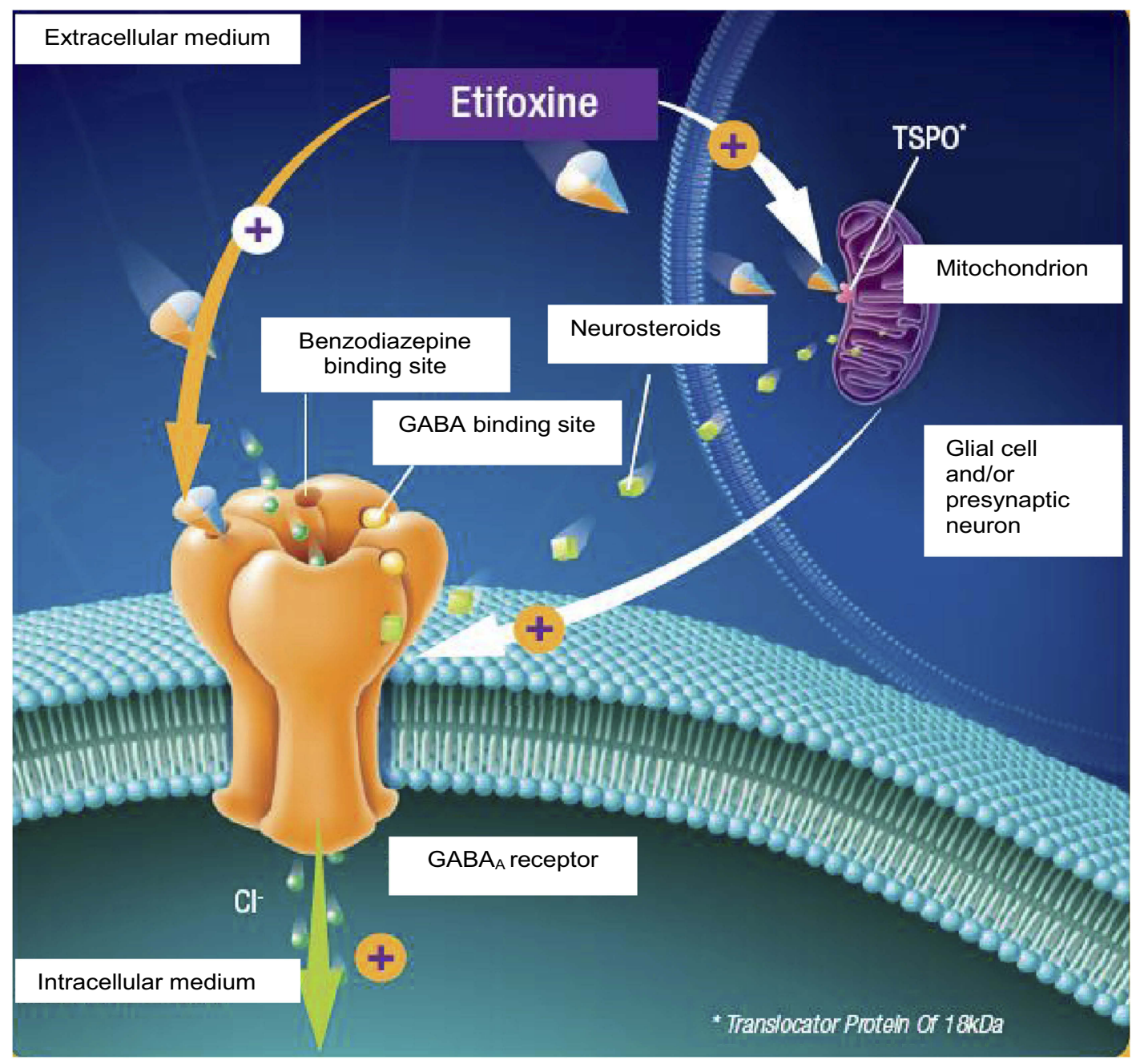

Figure 2 Mechanism of action of etifoxine. Etifoxine stimulates GABAergic transmission through two complementary mechanisms. Firstly, etifoxine binds directly to the $\boldsymbol{\beta}_{2} / \boldsymbol{\beta}_{3}$ subunits of the $G_{A B A}$ receptor. Secondly, etifoxine reinforces GABAergic transmission via an indirect mechanism by binding to the TSPO receptor on mitochondria, thus facilitating the synthesis of neurosteroids, which are powerful positive allosteric modulators of the $\mathrm{GABA}_{\mathrm{A}}$ receptor. Reproduced with kind permission from Biocodex.

agonist (DOI hydrochloride). The anxiolytic activity of etifoxine and gabapentin in this model, unlike that of diazepam, tended to persist during the test-retest procedure, albeit to a lesser extent than that of DOI hydrochloride. ${ }^{50}$ These data suggest that etifoxine and gabapentin may be more effective in treating anxiety manifestations of stress and fear than BZD.

\section{Anxiolytic activity of etifoxine: clinical trials and practice}

Anxiolytic activity of etifoxine: studies in patients

\section{Clinical pharmacology}

Studies have been conducted in healthy volunteers to characterize the pharmacokinetic profile of etifoxine. Following administration of a single dose of etifoxine
$(150 \mathrm{mg}$ ), the molecule is extremely bioavailable (approximately $90 \%$ ) and does not bind to blood cells. It does, however, strongly bind to plasma proteins (88-95\%). After oral administration, etifoxine is rapidly absorbed by the gastrointestinal tract. Time to maximum blood concentration is $2-3 \mathrm{hrs}$. It is rapidly metabolized in the liver to form several metabolites. One of these metabolites, diethyl-etifoxine, is active. It can also cross the placental barrier. Etifoxine's half-life is about $6 \mathrm{hrs}$, and that of its active metabolite is almost $20 \mathrm{hrs}$. It is mainly excreted in urine as metabolites, but is also excreted in bile. Small amounts are excreted in an unchanged form. ${ }^{51}$

\section{Clinical efficacy}

The first studies of etifoxine in the clinical development program to obtain marketing authorization were conducted 
in patients presenting with anxiety and mood disorders. Compared with sulpiride and placebo, etifoxine demonstrated efficacy in reducing anxiety symptoms and cardiovascular signs such as dyspnea and tachycardia.

As the anxiolytic effects of etifoxine in animal models have been most robustly demonstrated in stress models, clinical development in recent years has focused on patients with ADs, and chiefly ADWA, as per DSM-III and DSM-IV classifications. The recent changes in AD categorization in both the DSM and ICD systems need to be taken into consideration when interpreting studies of etifoxine conducted using the previous DSM classification of ADWA.

\section{Clinical studies in patients who have ADWA}

The first multicenter, randomized, controlled, double-blind study evaluating the efficacy of etifoxine vs buspirone in 170 patients with a primary diagnosis of ADWA was carried out in France in 1998 (Table 1). ${ }^{52}$ Patients were treated for 4 weeks with either etifoxine (150-200 mg/day; $\mathrm{n}=83$ ), or buspirone (15-20 mg/day; $\mathrm{n}=87)$. All patients presented with clinical anxiety at inclusion, according to their Hamilton Anxiety Rating Scale (HAM-A) score $(\geq 18)$. The primary endpoint was the HAM-A score at 4 weeks, adjusted to the baseline value. Secondary endpoints were the Clinical Global Impression (CGI) Scale-Global Improvement score and the CGI-Efficacy Index (relationship between anxiolytic efficacy and undesirable effects). ${ }^{53}$

Results showed the superiority of etifoxine over buspirone for the mean HAM-A score at 4 weeks $(p=0.05)$. Moreover, the etifoxine group had a significantly better CGI-Global Improvement score than the buspirone group from Day 7 of treatment onwards $(p<0.001$ on Day 7 , and $p=0.02$ on Days 14 and 28). Finally, the CGI-Efficacy Index on Days 14 and 28 was also better for etifoxine $(p=0.01$ and $p=0.05)$. The treatment arms did not differ in the number of adverse events. ${ }^{52}$ CNS-related adverse events (somnolence, vertigo, and headache) were reported in $40.7 \%$ of the etifoxine-treated patients and $58.6 \%$ of the patients in the buspirone group.

In a second multicenter, controlled, randomized doubleblind study, etifoxine was compared with lorazepam in outpatients with ADWA followed by general practitioners (Table 1). ${ }^{54}$ Patients received either etifoxine $(50 \mathrm{mg} 3$ times per day; $\mathrm{n}=93$ ) or lorazepam $(2 \mathrm{mg}$ /day divided into three administrations: $0.5 \mathrm{mg}$ morning and noon, and $1.0 \mathrm{mg}$ in the evenings; $\mathrm{n}=96$ ) for 28 days. All patients presented with clinical anxiety at inclusion, according to their HAM-A score $(\geq 20)$. The main efficacy assessment criterion was the HAM-A score on Day 28, adjusted to Day 0 . Secondary endpoints included CGI, Sheehan Disability Scale $^{56}$ and Social Adjustment Scale Self-Report ${ }^{57}$ scores. Both treatments were effective in reducing the HAM-A score from Day 7 onwards. The anxiolytic effect of etifoxine was noninferior to that of lorazepam (Schuirmann noninferiority test: $p=0.0002$ for HAM-A score on Day 28 , and $p=0.0001$ on Day 7). However, a higher number of patients responded to treatment, as expressed by a total decrease in the HAM-A score from baseline to Day 28 of $\geq 50 \%$, in the etifoxine group ( $72 \%$ vs $56 \% ; p=0.0288)$. The CGI score had improved in both treatment arms by Day 28, but more patients showed a marked improvement (CGI score $<3$ ) in the etifoxine group than in the lorazepam group $(p=0.022)$. The CGI-Efficacy Index on Day 28 was better for etifoxine $(p=0.038)$. The agents displayed comparable efficacy in reducing disability and improving social adjustment.

There was no significant difference in the number of adverse events between the groups receiving etifoxine or lorazepam. ${ }^{54}$ Somnolence was reported in $10.7 \%$ of the etifoxine-treated patients and in $18.7 \%$ of the lorazepamtreated patients. Performances on immediate and delayed free recall memory tests at 28 days were comparable in both treatment arms. Withdrawal symptoms were evaluated 1 week following treatment cessation. The number of patients who experienced rebound anxiety after treatment cessation was significantly greater $(p=0.034)$ in the lorazepam group (eight patients) than in the etifoxine group (one patient). ${ }^{54}$

In a study among patients with ADWA conducted in Russia, $^{58}$ the efficacy of etifoxine was compared with that of phenazepam, an anxiolytic BZD commonly used in Russia for the treatment of Ads (Table 1). This multicenter, open-label, randomized study recruited 90 patients, who received either etifoxine (150 mg/day) or phenazepam ( $1 \mathrm{mg} /$ day) for 6 weeks. The primary endpoint was HAM-A on Day 42, adjusted to Day 0. Secondary evaluation criteria were CGI-Severity, CGI-Global Improvement, and CGI-Efficacy Index. Both treatments resulted in equivalent reductions in anxiety scores, according to the least-square mean estimate for noninferiority (95\% etifoxine-phenazepam: $-3.2[-5.3 ;-1.1])$. A second approach, however, indicated that etifoxine was superior to phenazepam ( $p=0.003$ for HAM-A score on Day 42).More etifoxine recipients than phenazepam recipients showed a tendency to marked improvement (CGI score <3) 


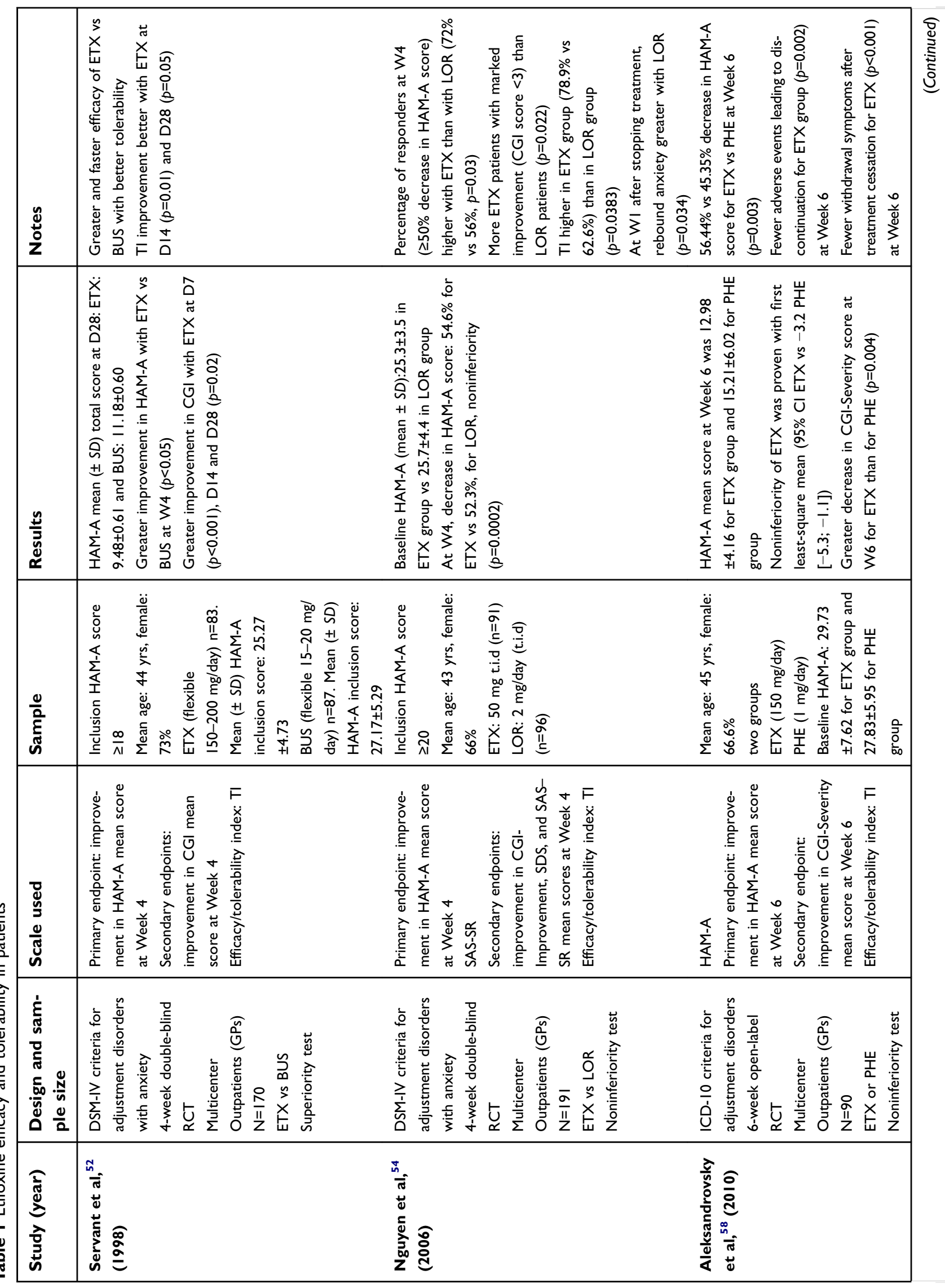




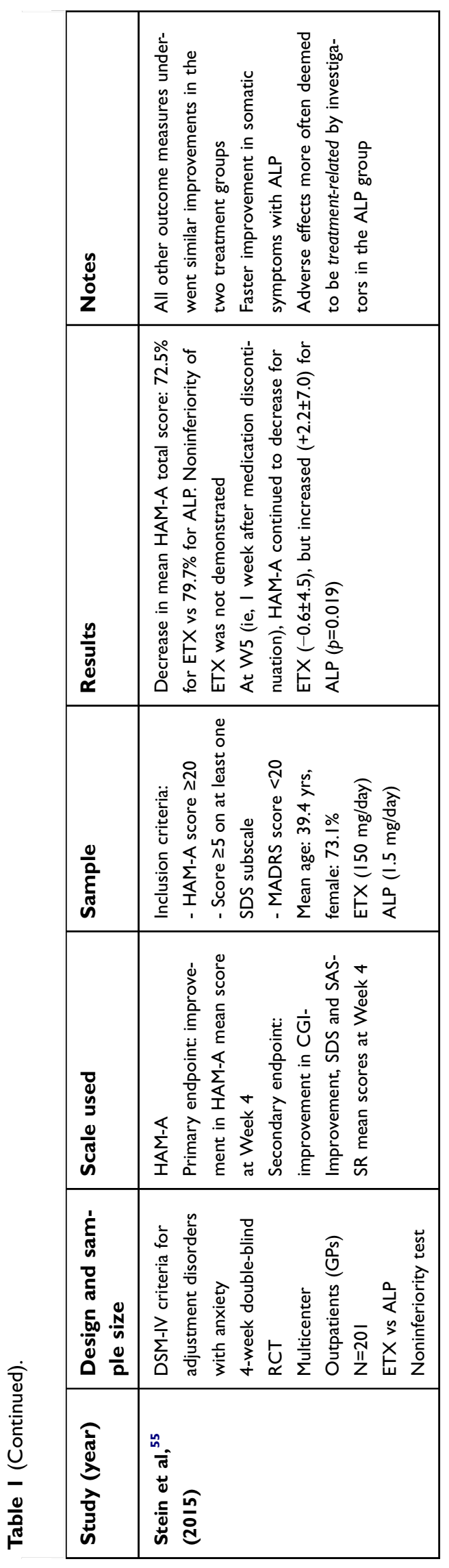

on Day 42. The CGI-Severity score fell in both groups, with a significant difference favoring etifoxine on Day 42 $(p=0.004)$. The CGI-Efficacy Index on Day 42 was also better for etifoxine $(p=0.004)$.

In this study, 23 of the 24 patients in the phenazepam group reported adverse events. The most frequently reported one was somnolence (observed in $32.6 \%$ of the phenazepam recipients). A significant difference was observed between the two treatment arms with respect to the number of adverse effects leading to discontinuation $(8$ in the phenazepam group vs 0 in the etifoxine group; $p=0.002) .{ }^{58}$ Concerning withdrawal symptoms after treatment cessation, three patients in the etifoxine group vs 26 in the phenazepam group experienced rebound anxiety between Days 42 and 49, according to the irHAM-A scores $(p<0.001){ }^{59}$

A multicenter, double-blind, randomized clinical trial evaluating the efficacy of etifoxine vs alprazolam in 201 outpatients with ADWA was recently conducted in South Africa (Table 1). ${ }^{55}$ Patients received either etifoxine $(150 \mathrm{mg} /$ day; $\mathrm{n}=100)$ or alprazolam $(1.5 \mathrm{mg} /$ day; $\mathrm{n}=101)$ for 4 weeks. All patients presented with clinical anxiety at inclusion, according to their HAM-A scores $(\geq 20)$. The primary endpoint was the total HAM-A score at Day 28, adjusted for its value at Day 1. Secondary endpoints included CGI-Global Improvement and the percentage of responders (defined by $\geq 50 \%$ decrease in HAM-A score between Days 1 and 28). Anxiety symptoms started to improve from the first week in both groups. By Day 28, the mean HAM-A total score had decreased by $72.5 \%$ in the etifoxine group and by $79.7 \%$ in the alprazolam group, while the adjusted mean difference in the HAM-A score was $1.78(90 \% \mathrm{CI}[0.23 ; 3.33])$ in favor of alprazolam. As the upper limit of the $90 \% \mathrm{CI}$ was greater than the 2.5 reference value, noninferiority of etifoxine to alprazolam was not demonstrated. One week after treatment discontinuation (Day 35), the HAM-A score in the etifoxine group was still decreasing, whereas it had started to climb in the alprazolam group, and the difference between the groups on the mean change between Days 28 and 35 was significant $(p=0.019)$. Similarly, the CGI-Severity score decreased between Days 28 and 35 in the etifoxine group, whereas it increased in the alprazolam group ( $p=0.004)$. Regarding the secondary outcome measures, there were no significant differences between the two groups, neither CGI scores nor responder status at Day 28.

During this study, 35 patients $(35 \%)$ in the etifoxine group experienced at least one adverse event, compared 
with 48 (47.5\%) in the alprazolam group. Adverse events were rated far more often as treatment-related by the investigators for the alprazolam group $(62.3 \% ; 13$ possibly and 25 probably related) than for the etifoxine group (34.3\%; 13 possibly and 11 probably related). Adverse events resulted in the withdrawal of seven patients from the etifoxine group and six patients from the alprazolam group, mainly owing to CNS or gastrointestinal symptoms. CNS symptoms (principally somnolence, sedation or fatigue) were reported by $16 \%$ of the etifoxine recipients and by $24.8 \%$ of the alprazolam recipients. Gastrointestinal symptoms were reported by 12 patients in the etifoxine group and eight in the alprazolam group. After treatment discontinuation, more patients (11\%) experienced adverse events in the alprazolam group (16 events) than in the etifoxine group ( $4 \%$ of the patients and 4 events) $(p=0.063)$. In the alprazolam group, $50 \%$ of these adverse events were treatment-related (five possible and three probable), compared with none in the etifoxine group.

These clinical studies clearly demonstrate the efficacy of etifoxine as an anxiolytic in patients with ADWA. They also highlight the good tolerability profile of etifoxine, particularly its preservation of cognitive function and vigilance. Moreover, etifoxine is not associated with either rebound anxiety or withdrawal symptoms following treatment cessation. ${ }^{60}$

\section{Pharmacovigilance}

Over the 30 years since etifoxine was first licensed, drug safety monitoring has confirmed the low risk of drug dependence or withdrawal symptoms following treatment cessation61 The few reported adverse events mostly concern skin and subcutaneous tissue disorders (eg, toxidermia), which generally resolve with treatment discontinuation. Hepatobiliary disorders such as elevated liver enzymes have been described, but their incidence is unknown. Elevated transaminase is generally reversible upon treatment discontinuation. As with any psychotropic drug, episodic liver function monitoring is recommended. Recent pharmacovigilance data are summarized in https://www.has-sante.fr.

\section{Cognitive effects of etifoxine in healthy individuals}

The psychomotor and memory effects of oral doses of etifoxine and lorazepam were compared in healthy participants in a randomized, double-blind, parallel-group placebo-controlled study ${ }^{62}$ (Table 2). A total of 48 healthy participants were assigned to one of four groups, to receive either a single dose of etifoxine $(50 \mathrm{mg}$ or $100 \mathrm{mg})$, a single dose of lorazepam (2 $\mathrm{mg}$ ), or placebo. Neuropsychological testing evaluated psychomotor performance (choice reaction time), attention (Barrage test), and memory (Digit Span, immediate and delayed free recall of a word list). A visual analog scale (VAS) was used to measure sedation and mood. Seven adverse events were reported by participants: five in the lorazepam group (sweating, intoxicated feeling, and three cases of somnolence), and one (somnolence) in the etifoxine group. Psychomotor performance at $2 \mathrm{hrs}$ differed between the four groups. Reaction times in the lorazepam group were significantly longer than in the other three groups $(p<0.001)$. In addition, lorazepam recipients gave fewer correct Barrage test answers than participants who had received $50 \mathrm{mg}$ etifoxine or placebo $(p<0.002)$. Both immediate and delayed free recall were significantly impaired by lorazepam $(p<0.001)$. The VAS results showed that at 2 and 4 hrs, lorazepam-treated participants experienced significantly more fatigue, drowsiness, somnolence, and clumsiness and felt less energetic than those in the other groups.

This study provided no evidence that the single oral doses of etifoxine (50 and $100 \mathrm{mg}$ ) had a deleterious effect on psychomotor performance, attention or memory, in comparison with the lorazepam $2 \mathrm{mg}$ used as a positive control.

In a recent publication, ${ }^{63} 30$ healthy older $(65-75$ years) volunteers were tested for alertness and cognitive functions in a study comparing etifoxine $(2 \dot{\times} 50 \mathrm{mg})$, lorazepam $(2 \dot{\times} 1 \mathrm{mg}$ ), and placebo (Table 2 ). The randomized placebo-controlled, double-blind, crossover design included three1-day sessions separated by a washout period of 14-30 days. Testing occurred 2 hrs after treatment administration. Participants underwent cognitive tests comprising the Cambridge Neuropsychological Test Automated Batteries and other psychological tests (Stroop, Rey, Auditory Verbal Learning Test, Digit Span). Reaction time was the primary efficacy criterion. Compared with placebo, etifoxine has no deleterious effect on alertness whereas, as expected, lorazepam significantly reduced it. In addition, etifoxine administration had no deleterious effects on attention, rapid visual information processing, Stroop test, or visuospatial, verbal, or working memory measures. Similar percentages of adverse events were observed with etifoxine and with placebo. Most were found after lorazepam administration. The most frequent adverse event was drowsiness. Only one adverse event 


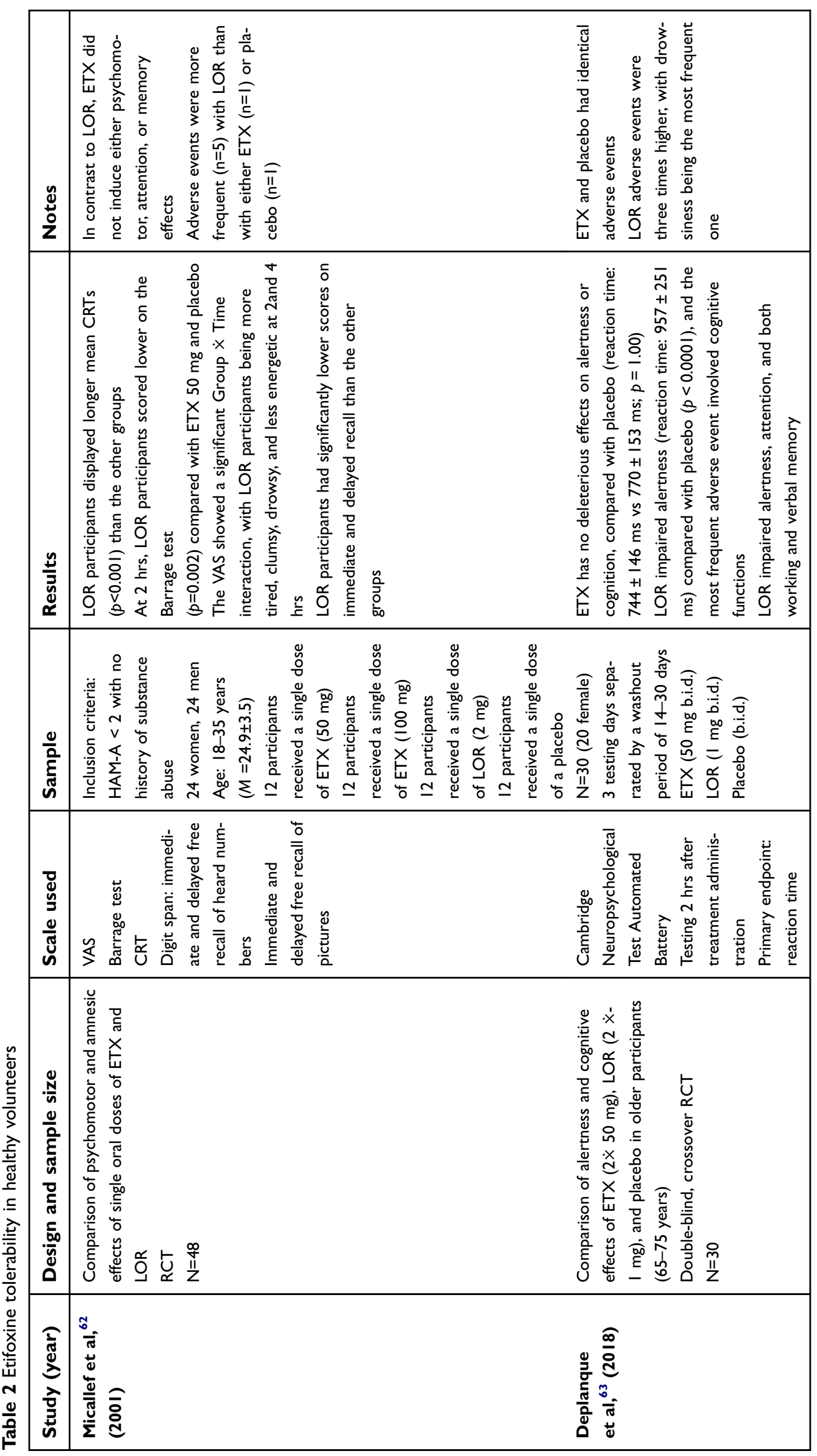


was rated as severe in the etifoxine group, compared with four in the lorazepam group.

\section{Neuroprotective activity of etifoxine in the central and peripheral nervous systems}

Etifoxine has also been found to have protective effects in animal models of neuroinflammation, nociception, and neurodegeneration, which may partially account for its beneficial effects in neurological and psychiatric disorders. ${ }^{64,65}$ Of particular interest is its activity in increasing the synthesis of neurotrophic factors known to be involved in neuroplasticity, which occurs in response to the development and chronicity of neuropsychiatric disorders, especially at the synaptic level. ${ }^{66,67}$ These studies also provide further support for the favorable tolerability profile of etifoxine compared with BZD. ${ }^{68}$

\section{Etifoxine enhances the synthesis of neuroprotective factors}

Several experimental procedures have been developed to examine the neuroprotective and neuroreparative properties of etifoxine. In a rat peripheral nerve lesion model (sciatic nerve cryolesion), Girard et al, demonstrated that etifoxine promotes peripheral nerve regeneration and axonal growth, leading to the accelerated and improved recovery of locomotion, motor coordination, and sensory functions. ${ }^{17}$ Etifoxine activity on neurite outgrowth has also been explored. Zhou et al, used a well-defined PC-12 cell model where etifoxine was found to promote the synthesis and release of glia-derived neurotrophic factor. ${ }^{69}$ Dai et al, showed that etifoxine increases neuronal-like outgrowth in PC-12 cells in a concentration-dependent manner. They also demonstrated that etifoxine improves sciatic nerve regeneration, modulates immune responses, and boosts neurotrophin expression. ${ }^{70}$ In a rat acellular nerve allograft model (for treating peripheral nerve injury), Zhou et al, reported that etifoxine increased the expression of neurofilaments in regenerated axons, improving sciatic nerve regeneration, increasing nerve conduction velocity, improving walking behaviors, and increasing neurotrophin expression. ${ }^{69}$

\section{Etifoxine has anti-inflammatory and immunomodulatory properties}

Several brain injury models have been used to evaluate the anti-inflammatory, immunomodulatory and neuroprotective effects of etifoxine. A potential neuroprotective effect of etifoxine was evaluated by $\mathrm{Li}$ et al, using a mouse model of middle cerebral artery occlusion (MCAO) and reperfusion. In this model, ischemia increased recruitment of certain microglial cell populations such as those expressing (ionized calcium-binding adaptor molecule 1 (Iba1+) and CD11b + CD45int. In these cells, TSPO activity was increased following ischemia. In this model, etifoxine significantly attenuated neurological deficits and infarct volume after MCAO and reperfusion. Etifoxine was shown to reduce the production of pro-inflammatory cytokines by microglia. In particular, decreases in interleukin-1 $\beta$, interleukin-6, tumor necrosis factor- $\alpha$, and inducible nitric oxide synthase were observed in the etifoxine-treated animals. ${ }^{71}$ More recently, in two mouse models of intracerebral hemorrhage, etifoxine $(50 \mathrm{mg} / \mathrm{kg} / \mathrm{day}$, IP route) was shown to significantly reduce neurological deficits and perihematomal brain edema up to 3 days post hemorrhage. This protective effect of etifoxine was associated with reduced leucocyte infiltration into the brain and increased production of IL- 6 and TNF $\alpha$ by microglial cells. ${ }^{72}$ Finally, in a model of traumatic brain injury, SimonO'Brien et al, demonstrated that etifoxine $(50 \mathrm{mg} / \mathrm{kg} / \mathrm{day} / 7$ days, IP route) reduced the production of pro-inflammatory cytokines, macrophage infiltration, glial activation, and neuronal degeneration. ${ }^{14}$

In a mono-arthritic rat model of pain, $50 \mathrm{mg} / \mathrm{kg}$ of etifoxine efficiently reduced neuropathic pain symptoms, whether the etifoxine was administered before or after induction of arthritis. Etifoxine was found to strengthen overall inhibition in the dorsal horn of the spinal cord, reducing several spinal inflammatory processes and protecting against PGE2induced glycinergic disinhibition. ${ }^{73}$ Using an experimental model of multiple sclerosis (experimental autoimmune encephalomyelitis; EAE), Daugherty et al, showed that etifoxine can decrease the severity of inflammatory demyelination and reduce infiltration of peripheral immune cells into the spinal cord. Again, this anti-inflammatory effect could be seen whether etifoxine was administered before or after induction of EAE. Recovery was correlated with diminished inflammatory pathology in the lumbar spinal cord and increased oligodendroglial regeneration. ${ }^{74}$ This effect of etifoxine may be mediated by modulation of TSPO activity, with etifoxine administration associated with an increase in $3 \alpha-$ hydroxysteroid dehydrogenase (ark1c14) mRNA levels.

\section{Protective effects of neurosteroidogenesis induced by etifoxine}

Injections of $50 \mathrm{mg} / \mathrm{kg}$ of etifoxine in adult male rats were found increase concentrations of pregnenolone, progesterone 
and its $5 \alpha$ - and $3 \alpha, 5 \alpha$-reduced metabolites in brain and plasma 30-60 mins after intraperitoneal administration. This response occurred within hours in the adrenal glands. ${ }^{75}$ Given this neurosteroidogenic property of etifoxine, its potential modulatory effect was investigated in a rat model of neuropathic pain induced by the anti-cancer agent vincristine. Prior administration of etifoxine prevented pain sensitization by vincristine and reduce established hyperalgesia. Endogenous synthesis of $3 \alpha, 5 \alpha$-reduced neurosteroids induced by etifoxine binding to TSPO appeared to be responsible for the observed anti-hyperalgesia effects. ${ }^{76}$ In a chronic sciatic nerve constriction rat model, Aouad et al, demonstrated that etifoxine suppresses neuropathic pain symptoms. This effect was fully mediated by $3 \alpha, 5 \alpha$-reduced neurosteroids, and probably also by allopregnanolone, which was found in high concentrations in the spinal cord of the treated animal. $^{77}$

\section{Conclusion}

Etifoxine is a non-BZD anxiolytic drug with selectivity for the $\beta$ subunit of the $\mathrm{GABA}_{\mathrm{A}}$ receptor. It possesses specific pharmacological properties, involving both direct and indirect (via neurosteroid synthesis) facilitation of GABAergic neurotransmission, leading to a potential indirect serotonergic activity. In addition, etifoxine attenuates CNS and whole-body inflammation and immunity processes known to be associated with anxiety.

Clinical studies have demonstrated the efficacy of etifoxine in the symptomatic treatment of anxiety, particularly in patients with ADWA, with daily doses of 150-200 mg. The tolerability profile of etifoxine is better than that of BZDs, notably because of a lack of effect on memory and vigilance. In addition, treatment cessation does not induce drug dependence, withdrawal, or rebound anxiety. The patients included in studies so far have mostly been women $(2 / 3)$, which corresponds to the sex ratio for anxiety and ADs in the general population. However, a gender effect of etifoxine cannot be ruled out.

Of note, a 1990 European Council resolution underscored the danger of inappropriate or excessive prescription of hypnotic or anxiolytic BZDs. ${ }^{78}$ This resolution recommended that prescribers restrict the use of anxiolytic BZDs to cases of severe or disabling anxiety and to limit treatment duration.

The anxiolytic efficacy of etifoxine, its good tolerability and the absence of drug dependence is strong arguments in favor of using etifoxine in the management of ADWA.

\section{Disclosure}

Dr. Nuss received a research grant and consultancy fees from Biocodex. The authors report no other conflicts of interest in this work.

\section{References}

1. Semaan W, Hergueta T, Bloch J, et al. [Cross-sectional study of the prevalence of adjustment disorder with anxiety in general practice]. Encephale. 2001;27(3):238-244.

2. Servant D, Pelissolo A, Chancharme L, Le Guern ME, Boulenger JP. [Adjustment disorders with anxiety. Clinical and psychometric characteristics in patients consulting a general practitioner]. Encephale. 2013;39(5):347-351. doi:10.1016/j.encep.2012.10.004

3. Poisbeau P, Gazzo G, Calvel L. Anxiolytics targeting GABAA receptors: insights on etifoxine. World J Biol Psychiatry. 2018;19(sup1): S36-S45. doi:10.1080/15622975.2018.1468030

4. Strain JJ. The psychobiology of stress, depression, adjustment disorders and resilience. World J Biol Psychiatry. 2018;19(sup1):S14S20. doi:10.1080/15622975.2018.1459049

5. Nuss P. Anxiety disorders and GABA neurotransmission: a disturbance of modulation. Neuropsychiatr Dis Treat. 2015;11:165-175. doi:10.2147/NDT.S58841

6. Hauger RL, Risbrough V, Brauns O, Dautzenberg FM. Corticotropin releasing factor (CRF) receptor signaling in the central nervous system: new molecular targets. CNS Neurol Disord Drug Targets. 2006;5(4):453-479.

7. Boyer P. Do anxiety and depression have a common pathophysiological mechanism? Acta Psychiatr Scand Suppl. 2000;(406):24-29. doi:10.1111/j.0065-1591.2000.acp29-04.x

8. Mehta AK, Ticku MK. An update on GABAA receptors. Brain Res Brain Res Rev. 1999;29(2-3):196-217.

9. Bandelow B, Baldwin D, Abelli M, et al. Biological markers for anxiety disorders, OCD and PTSD: a consensus statement. Part II: neurochemistry, neurophysiology and neurocognition. World J Biol Psychiatry. 2017;18(3):162-214. doi:10.1080/15622975.2016.1190867

10. Michopoulos V, Powers A, Gillespie CF, Ressler KJ, Jovanovic T. Inflammation in fear- and anxiety-based disorders: PTSD, GAD, and beyond. Neuropsychopharmacology. 2017;42(1):254-270. doi:10.1038/ npp.2016.146

11. Sharon G, Sampson TR, Geschwind DH, Mazmanian SK. The central nervous system and the gut microbiome. Cell. 2016;167(4):915-932. doi:10.1016/j.cell.2016.10.027

12. Cohen S, Janicki-Deverts D, Doyle WJ, et al. Chronic stress, glucocorticoid receptor resistance, inflammation, and disease risk. Proc Natl Acad Sci U S A. 2012;109(16):5995-5999. doi:10.1073/ pnas. 1118355109

13. Ghareghani M, Zibara K, Sadeghi H, et al. Fluvoxamine stimulates oligodendrogenesis of cultured neural stem cells and attenuates inflammation and demyelination in an animal model of multiple sclerosis. Sci Rep. 2017;7(1):4923. doi:10.1038/s41598-017-04968-z

14. Simon-O'Brien E, Gauthier D, Riban V, Verleye M. Etifoxine improves sensorimotor deficits and reduces glial activation, neuronal degeneration, and neuroinflammation in a rat model of traumatic brain injury. J Neuroinflammation. 2016;13(1):203. doi:10.1186/ s12974-016-0687-3

15. Juif PE, Melchior M, Poisbeau P. Characterization of the fast GABAergic inhibitory action of etifoxine during spinal nociceptive processing in male rats. Neuropharmacology. 2015;91:117-122. doi:10.1016/j.neuropharm.2014.12.022

16. Do Rego JL, Vaudry D, Vaudry H. The non-benzodiazepine anxiolytic drug etifoxine causes a rapid, receptor-independent stimulation of neurosteroid biosynthesis. PLoS One. 2015;10(3):e0120473. doi:10.1371/journal.pone. 0120473 
17. Girard C, Liu S, Cadepond F, et al. Etifoxine improves peripheral nerve regeneration and functional recovery. Proc Natl Acad Sci U S A. 2008;105(51):20505-20510. doi:10.1073/pnas.0811201106

18. Benham RS, Engin E, Rudolph U. Diversity of neuronal inhibition: a path to novel treatments for neuropsychiatric disorders. JAMA Psychiatry. 2014;71(1):91-93. doi:10.1001/jamapsychiatry.2013. 3059

19. Rudolph U, Crestani F, Mohler H. GABA(A) receptor subtypes: dissecting their pharmacological functions. Trends Pharmacol Sci. 2001;22(4):188-194.

20. Sigel E, Luscher BP. A closer look at the high affinity benzodiazepine binding site on GABAA receptors. Curr Top Med Chem. 2011;11 (2):241-246.

21. Olsen RW. GABAA receptor: positive and negative allosteric modulators. Neuropharmacology. 2018;136(Pt A):10-22. doi:10.1016/ j.neuropharm.2018.01.036

22. Kruse HJ, Kuch H. Etifoxine: evaluation of its anticonvulsant profile in mice in comparison with sodium valproate, phenytoin and clobazam. Arzneimittelforschung. 1985;35(1):133-135.

23. Hamon A. Etifoxine et récepteurs GABAA. Encephale. 2008; (Supplément 1):S29-34. doi:10.1016/S0013-7006(08)71389-7

24. Boissier JR, Simon P, Zaczinska M, Fichelle J. [Experimental psychopharmacologic study of a new psychotropic drug, 2-ethylamino6-chloro-4-methyl-4-phenyl-4H-3,1-benzoxazine]. Therapie. 1972;27 (2):325-338.

25. Verleye M, Schlichter R, Gillardin JM. Interactions of etifoxine with the chloride channel coupled to the GABA(A) receptor complex. Neuroreport. 1999;10(15):3207-3210.

26. Rupprecht R, Holsboer F. Neuroactive steroids: mechanisms of action and neuropsychopharmacological perspectives. Trends Neurosci. 1999;22(9):410-416.

27. Belelli D, Lambert JJ. Neurosteroids: endogenous regulators of the GABA(A) receptor. Nat Rev Neurosci. 2005;6(7):565-575. doi:10.1038/nrn1703

28. Verleye M, Pansart Y, Gillardin J. Effects of etifoxine on ligand binding to GABA(A) receptors in rodents. Neurosci Res. 2002;44 (2):167-172.

29. Squires RF, Casida JE, Richardson M, Saederup E. [35S]t-butylbicyclophosphorothionate binds with high affinity to brain-specific sites coupled to gamma-aminobutyric acid-A and ion recognition sites. Mol Pharmacol. 1983;23(2):326-336.

30. Hamon A, Morel A, Hue B, Verleye M, Gillardin JM. The modulatory effects of the anxiolytic etifoxine on GABA(A) receptors are mediated by the beta subunit. Neuropharmacology. 2003;45(3):293-303.

31. Korpi ER, Sinkkonen ST. GABA(A) receptor subtypes as targets for neuropsychiatric drug development. Pharmacol Ther. 2006;109(1-2):12-32. doi:10.1016/j.pharmthera.2005.05.009

32. Verleye M, Dumas S, Heulard I, Krafft N, Gillardin JM. Differential effects of etifoxine on anxiety-like behaviour and convulsions in $\mathrm{BALB} / \mathrm{cByJ}$ and $\mathrm{C} 57 \mathrm{BL} / 6 \mathrm{~J}$ mice: any relation to overexpression of central GABAA receptor beta2 subunits? Eur Neuropsychopharmacol. 2011;21(6):457-470. doi:10.1016/j.euroneuro.2010.09.008

33. Verleye M, Heulard I, Nuss P, Gillardin JM. Effects of stress and etifoxine on pentobarbital-induced loss of righting reflex in Balb/ cByJ and C57BL/6J mice. Neurosci Lett. 2003;353(2):127-130.

34. Schlichter R, Rybalchenko V, Poisbeau P, Verleye M, Gillardin J. Modulation of GABAergic synaptic transmission by the non-benzodiazepine anxiolytic etifoxine. Neuropharmacology. 2000;39(9): 1523-1535.

35. Selvaraj V, Tu LN. Current status and future perspectives: TSPO in steroid neuroendocrinology. $J$ Endocrinol. 2016;231(1):R1-R30. doi:10.1530/JOE-16-0241

36. Morohaku K, Pelton SH, Daugherty DJ, Butler WR, Deng W, Selvaraj V. Translocator protein/peripheral benzodiazepine receptor is not required for steroid hormone biosynthesis. Endocrinology. 2014;155(1):89-97. doi:10.1210/en.2013-1556
37. Tu LN, Morohaku K, Manna PR, et al. Peripheral benzodiazepine receptor/translocator protein global knock-out mice are viable with no effects on steroid hormone biosynthesis. J Biol Chem. 2014;289 (40):27444-27454. doi:10.1074/jbc.M114.578286

38. Tu LN, Zhao AH, Stocco DM, Selvaraj V. PK11195 effect on steroidogenesis is not mediated through the translocator protein (TSPO). Endocrinology. 2015;156(3):1033-1039. doi:10.1210/en.2014-1707

39. Majewska MD. Neurosteroids: endogenous bimodal modulators of the GABAA receptor. Mechanism of action and physiological significance. Prog Neurobiol. 1992;38(4):379-395.

40. Wolf L, Bauer A, Melchner D, et al. Enhancing neurosteroid synthesis-relationship to the pharmacology of translocator protein (18 $\mathrm{kDa}$ (TSPO) ligands and benzodiazepines. Pharmacopsychiatry. 2015;48(2):72-77. doi:10.1055/s-0034-1398507

41. Costa B, Cavallini C, Da Pozzo E, Taliani S, Da Settimo F, Martini C. The anxiolytic etifoxine binds to TSPO Ro5-4864 binding site with long residence time showing a high neurosteroidogenic activity. ACS Chem Neurosci. 2017;8(7):1448-1454. doi:10.1021/acschemneuro.7b00027

42. Verleye M, Akwa Y, Liere P, et al. The anxiolytic etifoxine activates the peripheral benzodiazepine receptor and increases the neurosteroid levels in rat brain. Pharmacol Biochem Behav. 2005;82(4):712-720. doi:10.1016/j.pbb.2005.11.013

43. Ugale RR, Sharma AN, Kokare DM, Hirani K, Subhedar NK, Chopde CT. Neurosteroid allopregnanolone mediates anxiolytic effect of etifoxine in rats. Brain Res. 2007;1184:193-201. doi:10.1016/j.brainres.2007.09.041

44. Verleye M, Heulard I, Gillardin JM. Investigation of the anticonvulsive effect of acute immobilization stress in anxious Balb/cByJ mice using GABA A-related mechanistic probes. Psychopharmacology (Berl). 2008;197(4):523-534. doi:10.1007/s00213-007-1066-7

45. Verleye M, Schlichter R, Neliat G, Pansart Y, Gillardin JM. Functional modulation of gamma-aminobutyric acid(A) receptors by etifoxine and allopregnanolone in rodents. Neurosci Lett. 2001;301(3):191-194.

46. Bourin M, Hascoet M. Implication of 5-HT2 receptor subtypes in the mechanism of action of the GABAergic compound etifoxine in the four-plate test in Swiss mice. Behav Brain Res. 2010;208 (2):352-358. doi:10.1016/j.bbr.2009.11.046

47. Verleye M, Gillardin JM. Effects of etifoxine on stress-induced hyperthermia, freezing behavior and colonic motor activation in rats. Physiol Behav. 2004;82(5):891-897. doi:10.1016/j.physbeh.2004.07.010

48. Verleye M, Andre N, Gillardin JM. Lack of interaction between etifoxine and CRF1 and CRF2 receptors in rodents. Neurosci Res. 2006;56(1):53-60. doi:10.1016/j.neures.2006.05.005

49. Verleye M, Heulard I, Gillardin JM. The anxiolytic etifoxine protects against convulsant and anxiogenic aspects of the alcohol withdrawal syndrome in mice. Alcohol. 2009;43(3):197-206. doi:10.1016/j. alcohol.2009.02.003

50. Bourin M, Hascoet M. Insight into the mechanism of the four-plate test-retest procedure using etifoxine as compared with gabapentin. Current Psychopharmacology. 2012;1(1):2-8. doi:10.2174/ 2211556011201010002

51. Choi YM, Kim KH. Etifoxine for pain patients with anxiety. Korean J Pain. 2015;28(1):4-10. doi:10.3344/kjp.2015.28.1.4

52. Servant D, Graziani PL, Moyse D, Parquet PJ. [Treatment of adjustment disorder with anxiety: efficacy and tolerance of etifoxine in a double-blind controlled study]. Encephale. 1998;24 (6):569-574.

53. Rickels K, Howard K, Guy W. Clinical Global Impressions. In: ECDEU Assessment Manual for Psychopharmacology. Washington (DC): U.S. Government Printing Office; DHEW Publication; 1976:218-222.

54. Nguyen N, Fakra E, Pradel V, et al. Efficacy of etifoxine compared to lorazepam monotherapy in the treatment of patients with adjustment disorders with anxiety: a double-blind controlled study in general practice. Hum Psychopharmacol. 2006;21(3):139-149. doi:10.1002/ hup. 757 
55. Stein DJ. Etifoxine versus alprazolam for the treatment of adjustment disorder with anxiety: a randomized controlled trial. Adv Ther. 2015;32(1):57-68. doi:10.1007/s12325-015-0176-6

56. Leon AC, Olfson M, Portera L, Farber L, Sheehan DV. Assessing psychiatric impairment in primary care with the Sheehan Disability Scale. Int J Psychiatry Med. 1997;27(2):93-105. doi:10.2190/T8EMC8YH-373N-1UWD

57. Weissman MM, Bothwell S. Assessment of social adjustment by patient self-report. Arch Gen Psychiatry. 1976;33(9):1111-1115.

58. Alexandrovsky YA, Krasnov VN, Neznanov NG, Romasenko LV. Efficacy of etifoxine in comparison with phenazepam in the treatment of patients with adjustment disorders (an open randomized controlled study). Russian J Psychiatry. 2010;1:74-78. Russian.

59. Hamilton M. The assessment of anxiety states by rating. $\mathrm{Br} \mathrm{J} \mathrm{Med}$ Psychol. 1959;32(1):50-55.

60. Stein DJ. Pharmacotherapy of adjustment disorder: A review. The World Journal of Biological Psychiatry. 2018;19(sup1):S46-S52. DOI: $10.1080 / 15622975.2018 .1492736$

61. Cottin J, Gouraud A, Jean-Pastor MJ, et al. Safety profile of etifoxine: a French pharmacovigilance survey. Fundam Clin Pharmacol. 2016;30(2):147-152. doi:10.1111/fcp.12169

62. Micallef J, Soubrouillard C, Guet F, et al. A double blind parallel group placebo controlled comparison of sedative and mnesic effects of etifoxine and lorazepam in healthy subjects [corrected]. Fundam Clin Pharmacol. 2001;15(3):209-216.

63. Deplanque D, Machuron F, Waucquier N, et al. Etifoxine impairs neither alertness nor cognitive functions of the elderly: a randomized, double-blind, placebo-controlled crossover study. Eur Neuropsychopharmacol. 2018;28(8):925-932. doi:10.1016/j. euroneuro.2018.05.011

64. Rupprecht R, Papadopoulos V, Rammes G, et al. Translocator protein $(18 \mathrm{kDa})(\mathrm{TSPO})$ as a therapeutic target for neurological and psychiatric disorders. Nat Rev Drug Discov. 2010;9(12):971-988. doi:10.1038/ $\operatorname{nrd} 3295$

65. Gazzo G, Girard P, Kamoun N, Verleye M, Poisbeau P. Analgesic and anti-edemic properties of etifoxine in models of inflammatory sensitization. Eur J Pharmacol. 2019;843:316-322. doi:10.1016/j. ejphar.2018.12.018

66. Autry AE, Monteggia LM. Brain-derived neurotrophic factor and neuropsychiatric disorders. Pharmacol Rev. 2012;64(2):238-258. doi:10.1124/pr.111.005108

67. Mariga A, Mitre M, Chao MV. Consequences of brain-derived neurotrophic factor withdrawal in CNS neurons and implications in disease. Neurobiol Dis. 2017;97(Pt B):73-79. doi:10.1016/j.nbd.2016.03.009
68. Nothdurfter C, Rammes G, Baghai TC, et al. TSPO (18 kDa) as a target for novel anxiolytics with a favourable side-effect profile. $J$ Neuroendocrinol. 2011:24(1):82-92

69. Zhou X, He X, He B, et al. Etifoxine promotes glialderived neurotrophic factorinduced neurite outgrowth in PC12 cells. Mol Med Rep. 2013;8(1):75-80. doi:10.3892/mmr.2013.1474

70. Dai T, Zhou X, Li Y, et al. Etifoxine promotes glia-derived neurite outgrowth in vitro and in vivo. $J$ Reconstr Microsurg. 2014;30 (6):381-388. doi:10.1055/s-0034-1381751

71. Li HD, Li M, Shi E, et al. A translocator protein $18 \mathrm{kDa}$ agonist protects against cerebral ischemia/reperfusion injury. $J$ Neuroinflammation. 2017;14(1):151. doi:10.1186/s12974-017-0921-7

72. Li M, Ren H, Sheth KN, Shi FD, Liu Q. A TSPO ligand attenuates brain injury after intracerebral hemorrhage. Faseb J. 2017;31 (8):3278-3287. doi:10.1096/fj.201601377RR

73. Aouad M, Zell V, Juif PE, et al. Etifoxine analgesia in experimental monoarthritis: a combined action that protects spinal inhibition and limits central inflammatory processes. Pain. 2014;155(2):403-412. doi:10.1016/j.pain.2013.11.003

74. Daugherty DJ, Selvaraj V, Chechneva OV, Liu XB, Pleasure DE, Deng W. A TSPO ligand is protective in a mouse model of multiple sclerosis. EMBO Mol Med. 2013;5(6):891-903. doi:10.1002/ emmm.201202124

75. Liere P, Pianos A, Oudinet JP, Schumacher M, Akwa Y. Differential effects of the 18-kDa translocator protein (TSPO) ligand etifoxine on steroidogenesis in rat brain, plasma and steroidogenic glands: pharmacodynamic studies. Psychoneuroendocrinology. 2017;83:122-134. doi:10.1016/j.psyneuen.2017.05.022

76. Aouad M, Charlet A, Rodeau JL, Poisbeau P. Reduction and prevention of vincristine-induced neuropathic pain symptoms by the non-benzodiazepine anxiolytic etifoxine are mediated by 3alpha-reduced neurosteroids. Pain. 2009;147(1-3):54-59. doi:10.1016/j.pain.2009.08.001

77. Aouad M, Petit-Demouliere N, Goumon Y, Poisbeau P. Etifoxine stimulates allopregnanolone synthesis in the spinal cord to produce analgesia in experimental mononeuropathy. Eur J Pain. 2014;18 (2):258-268. doi:10.1002/j.1532-2149.2013.00367.x

78. Council of Europe. Committee of ministers. Resolution AP (90) 3 on the prescription of benzodiazepines. $J$ Gen Microbiol. 1990;136:327-330. doi:10.1099/00221287-136-2-327
Neuropsychiatric Disease and Treatment

\section{Publish your work in this journal}

Neuropsychiatric Disease and Treatment is an international, peerreviewed journal of clinical therapeutics and pharmacology focusing on concise rapid reporting of clinical or pre-clinical studies on a range of neuropsychiatric and neurological disorders. This journal is indexed on PubMed Central, the 'PsycINFO' database and CAS, and is the official journal of The International Neuropsychiatric Association (INA). The manuscript management system is completely online and includes a very quick and fair peer-review system, which is all easy to use. Visit http://www.dovepress.com/testimonials.php to read real quotes from published authors. 